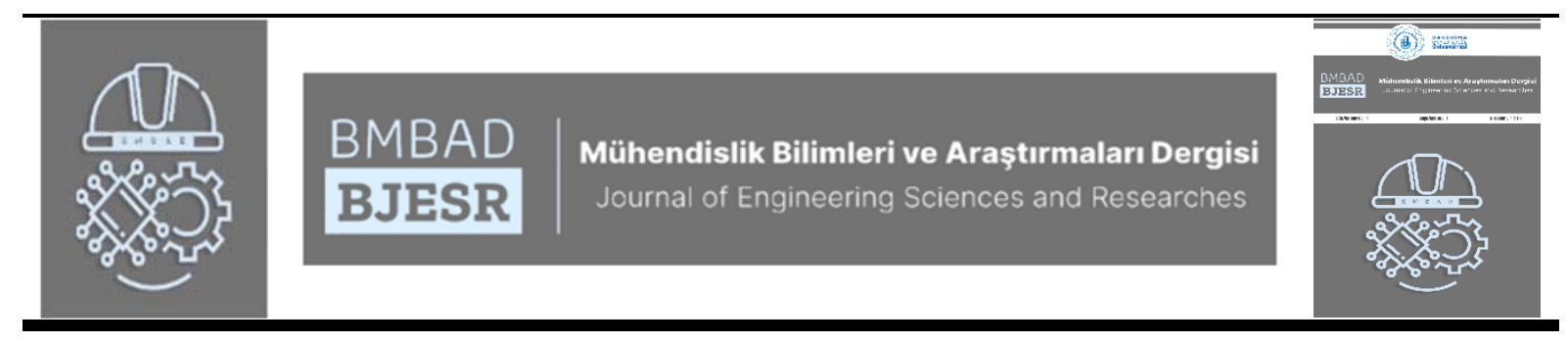

\title{
Çelik Levhalı Perde-Çerçeve Binaların Dinamik Analizi İçin Bir Yaklaşım
}

\author{
An Approach To Dynamic Analysis Of Steel Plate Shear Wall-Frame Buildings \\ ${ }^{1}$ Yasin Güngör (D), ${ }^{2}$ Kanat Burak Bozdoğan \\ ${ }^{I}$ Çanakkale Onsekiz Mart Üniversitesi, Lisansüstü Eğitim Enstitüsü, Çanakkale, Türkiye \\ ${ }^{2}$ Çanakkale Onsekiz Mart Üniversitesi, Mühendislik Fakültesi, Çanakkale, Türkiye
}

119214401005@ogr.comu.edu.tr,2kbbozdogan@comu.edu.tr

Araştırma Makalesi/Research Article

\begin{tabular}{l}
\hline A R T I C L E I N F O \\
Article history \\
Received :3 March 2021 \\
Accepted : 11 March 2021 \\
\end{tabular}

A B S T R A C T

One of the bearing systems used against earthquake in steel buildings is a steel plate wall-frame systems. In this study, an approach is proposed for dynamic analysis of buildings consisting of steel plate wall-frame systems whose material and geometric properties are uniform throughout the height of the building. In this study, the continuous system calculation model was adapted to the dynamic analysis of steel plate wall-frame systems. With the presented method, dynamic characteristics of the buildings such as period and effective mass can be determined, as well as peak displacement and base

Keywords:

Steel Plate Shear Wall, SPSW, Free Vibration Analysis, Spectral Analysis, Continuum Approximation Model shear force can be obtained easily with spectral analysis. At the end of the article, an example taken from the literature was solved with both the presented method and the SAP2000 program and the results obtained were compared. As a result, it has been observed that the presented method gives results close enough to the finite element method.

(C) 2020 Bandirma Onyedi Eylul University, Faculty of Engineering and Natural Science. Published by Dergi Park. All rights reserved.

M A K A L E B İ L G İ S İ

Makale Tarihleri

Gönderim : 3 Mart 2021

Kabul : 11 Mart 2021

Anahtar Kelimeler:

Çelik Levhalı Perde Duvar, ÇLPD, Serbest Titreşim Analizi, Spektral Analiz, Sürekli Sistem Hesap

\section{Ö Z E T}

Çelik binalarda depreme karşı kullanılan taşıyıcı sistemlerden birisi de çelik levhalı perde-çerçeve sistemlerdir. Bu çalışmada, malzeme ve geometrik özellikleri bina yüksekliği boyunca üniform olan çelik levhalı perde-çerçeve sistemlerden oluşan binaların dinamik analizi için bir yaklaşım önerilmiştir. Çalışmada sürekli sistem hesap modeli, çelik levhalı perde-çerçeve sistemlerin dinamik analizine uyarlanmıştır. Sunulan yöntemle binanın periyot, etkin kütle gibi dinamik karakteristikleri belirlenebildiği gibi, spektral analiz ile tepe noktası deplasmanı ve taban kesme kuvveti de kolay bir şekilde elde edilmektedir. Makalenin sonunda, literatürden alınmış olan bir örnek hem sunulan yöntem ile hem de SAP2000 programı ile çözülmüş ve elde edilen sonuçlar karşılaştırılmıştır. Sonuç olarak sunulan yöntemin, sonlu elemanlar yöntemine yeter derecede yakın sonuçlar verdiği gözlenmiştir.

(C) 2020 Bandırma Onyedi Eylül Üniversitesi, Mühendislik ve Dağa Bilimleri Fakültesi. Dergi Park tarafından yayınlanmaktadır. Tüm Hakları Saklıdır. 


\section{GİRIŞ}

Deprem bölgelerinde inşa edilen tüm binalarda taşı1ııı sistemin deprem ve rüzgâr gibi yüklere karşı yanal rijitliği önem arz etmektedir. Yatay yüklerin karşılanmasında betonarme perdeler, çelik çaprazlar ve moment aktaran kolon-kiriş birleşimli rijit çerçeveler akla gelmektedir. Tüm bunlara ek olarak 1970'li yıllardan itibaren Amerika, Kanada ve Japonya gibi ülkelerdeki çelik binalarda, çelik levhalı perde duvarlar (ÇLPD) kullanılmaya başlanmıştır. Yıllar geçtikçe kullanımı ve çalışma alanları artan bu sistemlerin dinamik davranışı konusunda halen çalışmalar devam etmektedir. Aşağıda kısaca literatürde yapılan çalışmalar özetlenmiştir.

Love vd. ÇLPD sistemini bir hastane binasını rijitleştirmek ve güçlendirmek için kullanmışlardır [1]. Bhowmick vd., deprem sırasında çelik levhaların veriminin, tüm katlarda gerçekleşmesinin beklenmeyeceğini kabul eden rasyonel bir tasarım yöntemi ile daha ekonomik bir ÇLPD çözümünü önermiş̧lerdir [2]. Alavi ve Nateghi, çapraz olarak güçlendirilmiş ÇLPD sistemlerin davranışını incelemişlerdir [3]. Nie vd., çok açıklıklı ÇLPD sistemlerin davranışlarını deneysel olarak araştırmışlardır [4]. Koppal ve Eatherton, çevresi boyunca dairesel delikler veya kelebek şekilli kesikler içeren yeni bir ÇLPD sistemi önermişlerdir [5]. Bhowmick vd. dairesel delikli bir ÇLPD sistemine ait kayma mukavemetinin boşluksuz ÇLPD sistemlerin kayma mukavemeti değerlerine bağlı olarak hesaplanabileceğini göstermişlerdir [6]. Asl ve Safarkhani, ÇLPD etrafındaki çerçeve konfigürasyonunun, sistemin sünekliğinde önemli rol oynadığını belirtmişler ve kiriş-kolon bağlantılarındaki gevrek kırılmayı önlemek için, kirişlerin zayıflatılabileceği birtakım yöntemler önermişlerdir [7]. Dowden ve Bruneau kirişten kolona bağlantı şekilleri bulunan, art germeli ve kendinden merkezlemeli ÇLPD sistemlerinin davranışlarını deneysel olarak incelemişlerdir [8]. Wang ve Xie ince ÇLPD sistemlerindeki iki ana sorun olan H-kesitli çelik kolon tabanının burkulması ve histerik eğrilerdeki sıkıştırma etkisine karşı çözüm önerisi sunmuşlardır [9]. Yu vd. enine köşebentlerle çapraz tutturulmuş ÇLPD sistemlerin döngüsel performansını incelemişlerdir [10].

$\mathrm{Bu}$ çalışmada ise sürekli sistem hesap modeli çelik levhalı perde-çerçeve taşıyıcı sisteme sahip binaların dinamik analizine uyarlanmıştır. Sunulan yaklaşımın geliştirilmesinde;

a) Malzemenin lineer elastik olduğu,

b) Geometrik nonlineer etkilerin ihmal edilebilecek mertebede olduğu,

c) Kolonlarda ve levha perdede kayma yer değiştirmelerinin ihmal edilebilecek mertebede olduğu,

d) Kirişlerde kayma ve eksenel yer değiştirmelerin ihmal edilebilecek mertebede olduğu,

e) Yapı geometrik özelliklerinin yapı yüksekliği boyunca üniform olduğu,

f) Taşıyıcı sistemlerin planda simetrik yerleştirildiği dolayısıyla bina düşey ekseni boyunca burulma etkilerinin ihmal edilebileceği, kabulleri yapılmıştır.

\section{YÖNTEM}

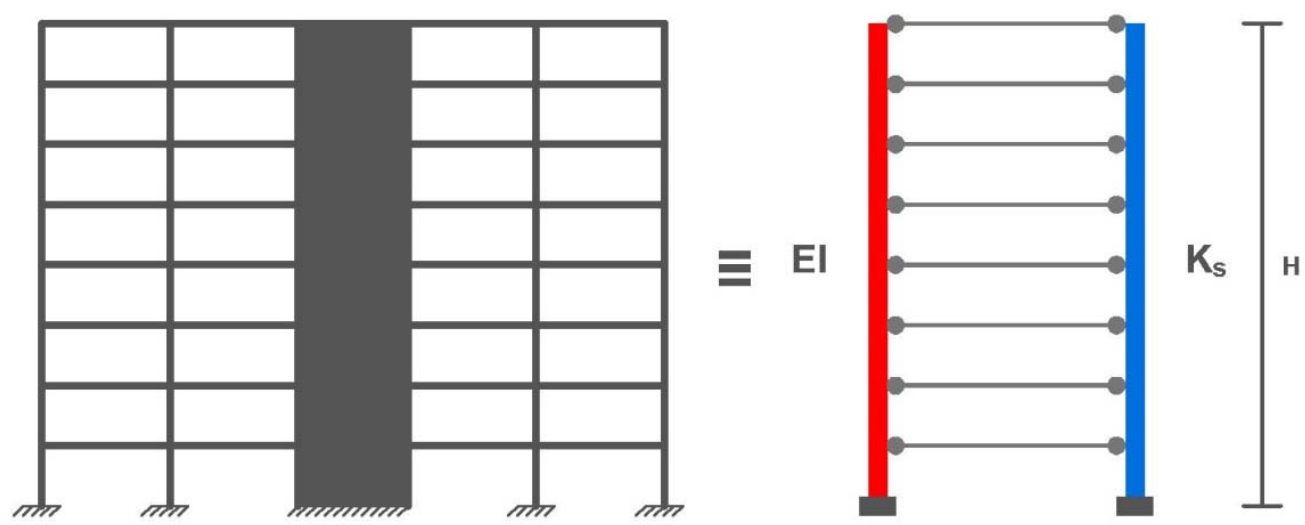

Şekil 1. Eşdeğer eğilme-kayma kirişi modeli

Sürekli sistem hesap modeline göre çelik levhalı perde-çerçeve sistem eşdeğer bir eğilme kayma kirişi olarak Şekil 1'deki gibi modellenebilir. Eşdeğer sistemin diferansiyel denklemi aşağıdaki gibi yazılabilir [11,12].

$(E I) \frac{d^{4} y}{d z^{4}}-K_{s} \frac{d^{2} y}{d z^{2}}-\bar{m} \omega^{2} \frac{d^{2} y}{d t^{2}}=0$

Burada y yatay yer değiştirme fonksiyonunu, z bina düşey ekseni boyunca uzanan ekseni göstermektedir. EI eşdeğer eğilme rijitliğini göstermekte olup levhalı perde sistemin eğilme rijitliği ile kolonların eğilme rijitlikleri toplamından oluşmaktadır. $K_{s}$ ise eşdeğer kayma rijitliğini göstermektedir. $K_{s}$ eşdeğer kayma riitliğinin bulunması için farklı bağıntılar literatürde verilmiştir $[11,13,14,15]$.

(1) nolu denklemdeki $\bar{m}$ bina yüksekliği boyunca yayılı kütleyi, $\omega$ ise açısal frekansı göstermektedir.

(1) numaralı denklem boyutsuz olarak aşağıdaki gibi yazılır. 
$\frac{d^{4} y}{d \varepsilon^{4}}-k^{2} \frac{d^{2} y}{d \varepsilon^{2}}-\alpha y=0$

Burada k ve $\alpha$ boyutsuz parametreleri aşağıdaki gibi tanımlanmıştır.

$k=H \sqrt{\frac{K_{S}}{(E I)}}$

$\alpha=\frac{\bar{m} H^{4} \omega^{2}}{(E I)}$

(2) nolu denklemin sınır koşulları dikkate alınarak çözümünden mod şekli fonksiyonu aşağıdaki gibi elde edilir.

$\mathrm{y}=\left[\cosh \left(\mathrm{a}_{1} \varepsilon\right)-\cos \left(\mathrm{a}_{2} \varepsilon\right)\right]+\mathrm{E}\left[\sinh \left(\mathrm{a}_{1} \varepsilon\right)-\frac{\mathrm{a}_{1}}{\mathrm{a}_{2}} \sin \left(\mathrm{a}_{2} \varepsilon\right)\right]$

Burada $\mathrm{a}_{1}, \mathrm{a}_{2}$ ve $\mathrm{E}$ ifadeleri aşağıdaki gibi tanımlıdır.

$\mathrm{a}_{1}=\sqrt{\frac{k^{2}+\sqrt{k^{4}+4 \alpha}}{2}}$

$\mathrm{a}_{2}=\sqrt{\frac{-k^{2}+\sqrt{k^{4}+4 \alpha}}{2}}$

$E=-\frac{\left[\mathrm{a}_{1}^{2} \cosh \left(\mathrm{a}_{1}\right)+\mathrm{a}_{2}^{2} \cos \left(\mathrm{a}_{2}\right)\right]}{\left[\mathrm{a}_{1}^{2} \sinh \left(\mathrm{a}_{1}\right)+\mathrm{a}_{1} \mathrm{a}_{2} \sin \left(\mathrm{a}_{2}\right)\right]}$

Periyotlar ise aşağıdaki bağıntı ile hesaplanır.

$T_{i}=\frac{Z_{i} H^{2}}{\Psi_{d}} \sqrt{\frac{m}{h(E I)}}$

Burada $\oiint_{\mathrm{d}}$ sürekli kütle modelini ayrık kütleye dönüştürmek için tanımlanmış bir düzeltme katsayısı olup aşağıdaki bağıntı ile hesaplanır [16].

$\Psi_{d}=\sqrt{\frac{n}{n+2,06}}$

n, kat sayısını göstermektedir.

Bina yüksekliği arttıkça eksenel yer değiştirmelerin önemi artmaktadır. Bu etki $\mathrm{K}_{\mathrm{s}}$ kayma rijitliği değerinde bir düzeltme yapılarak dikkate alınabilir $[12,16]$.

$K_{s e}=\xi K_{s}$

Burada $\xi$ aşağıdaki gibi tanımlıdır [16.]

Eksenel yer değiştirmelerin katkısını dikkate almak üzere (3) nolu bağıntıda k hesaplanırken $\mathrm{K}_{\mathrm{s}}$ yerine $\mathrm{K}_{\text {se }}$ kullanılmalıdır.

$\xi=\frac{f_{b}^{2}}{f_{b}^{2}+f_{s}^{2}}$

(12) nolu bağıntıdaki $\mathrm{f}_{\mathrm{b}}$ ve $\mathrm{f}_{\mathrm{s}}$ ise aşağıdaki gibi tanımlıdır.

$f_{S}^{2}=\frac{K_{S}}{(4 H)^{2} \bar{m}}$

$f_{b}^{2}=\frac{0.313 E I_{g}}{(H)^{4} \bar{m}}$

$I_{g}$ eksenel yer değiştirmelerle ilgili olan global eğilme rijitliği olup aşağıdaki bağıntı ile hesaplanır [12].

$I_{g}=\sum A_{c i} d_{i}^{2}$

Burada $\mathrm{A}_{\mathrm{ci}}$ i. kolonun kesit alanını, $\mathrm{d}_{\mathrm{i}}$ ise i. kolonun kesit alanlarının merkezine olan uzaklığını göstermektedir. 
(9) nolu denklemdeki Z değerlerinin ilk üç mod için k ya bağlı değişimi Şekil 2'de verilmiştir [12].

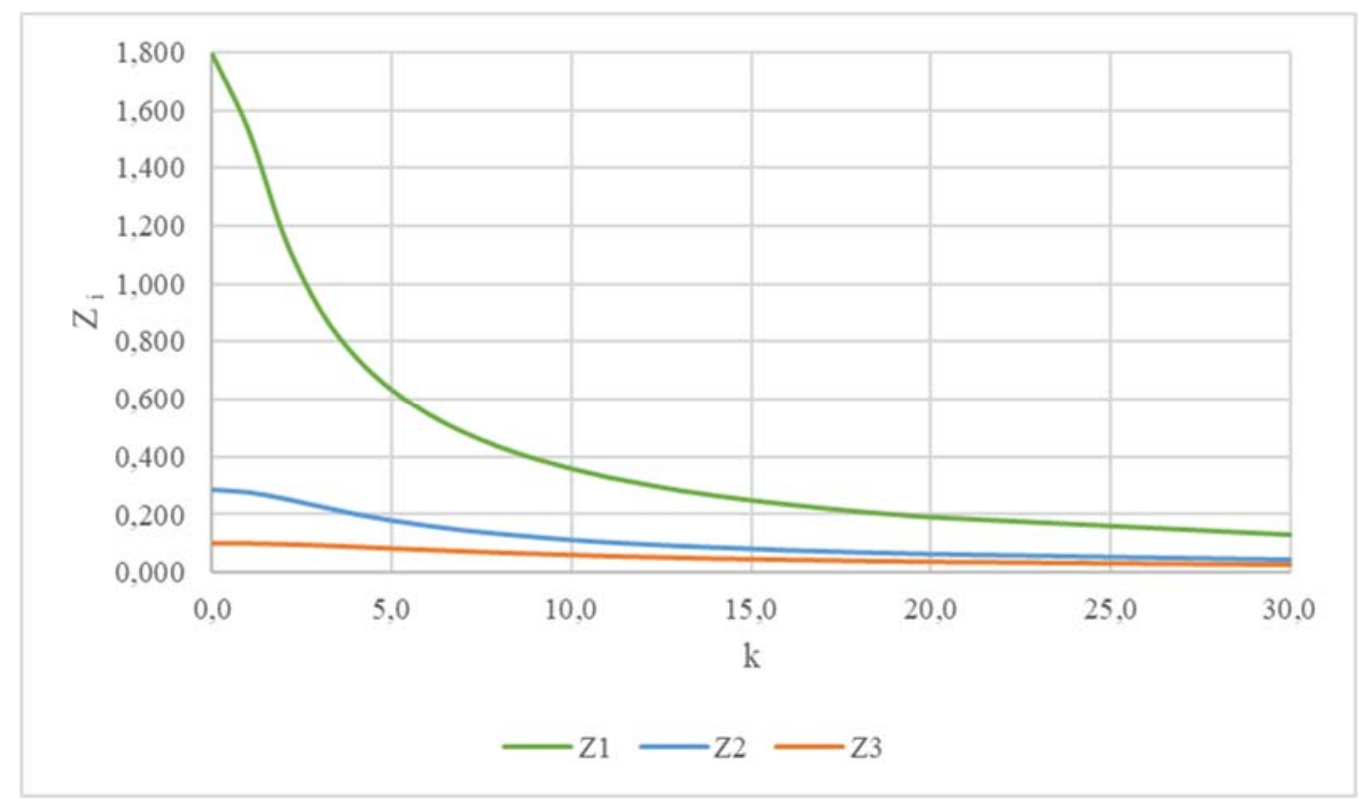

Şekil 2. İlk üç mod için $Z_{\mathrm{i}}$ değerleri

Tepe noktası deplasmanı için ise aşağıdaki bağıntı geçerlidir [12].

$\operatorname{dep}_{i}=\Gamma_{i} y_{i}(1) S_{d i}=\mu_{i} S_{d i}$

Burada $S_{\text {di }}$ i. mod için spektral yer değiştirme değerini göstermektedir. $\mu$ değerlerinin ilk üç mod için $\mathrm{k}$ ya bağlı değişimi Şekil 3’te verilmiştir.

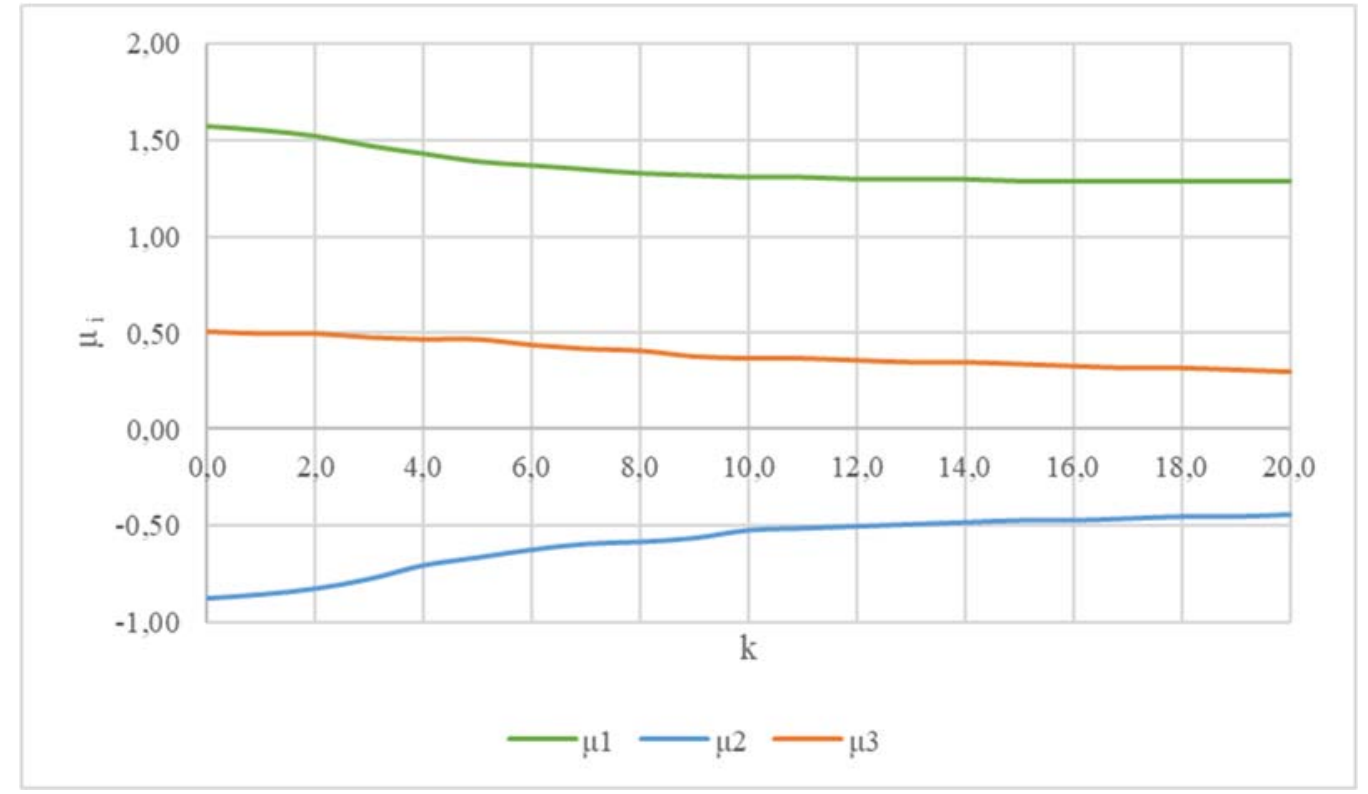

Şekil 3. İlk üç mod için $\mu$ değerleri

Taban kesme kuvveti ise aşă̆ıdaki bağıntı ile hesaplanabilir [12].

$V_{T i}=M \times e k o_{i} \times S_{a i}$

Burada $\mathrm{S}_{\mathrm{ai}}$ i. mod için spektral ivme değeridir. Bağıntıdaki etkin kütle oranlarının ilk üç mod için k’ya bağlı değişimi Şekil 4'teki grafikte sunulmuştur. 


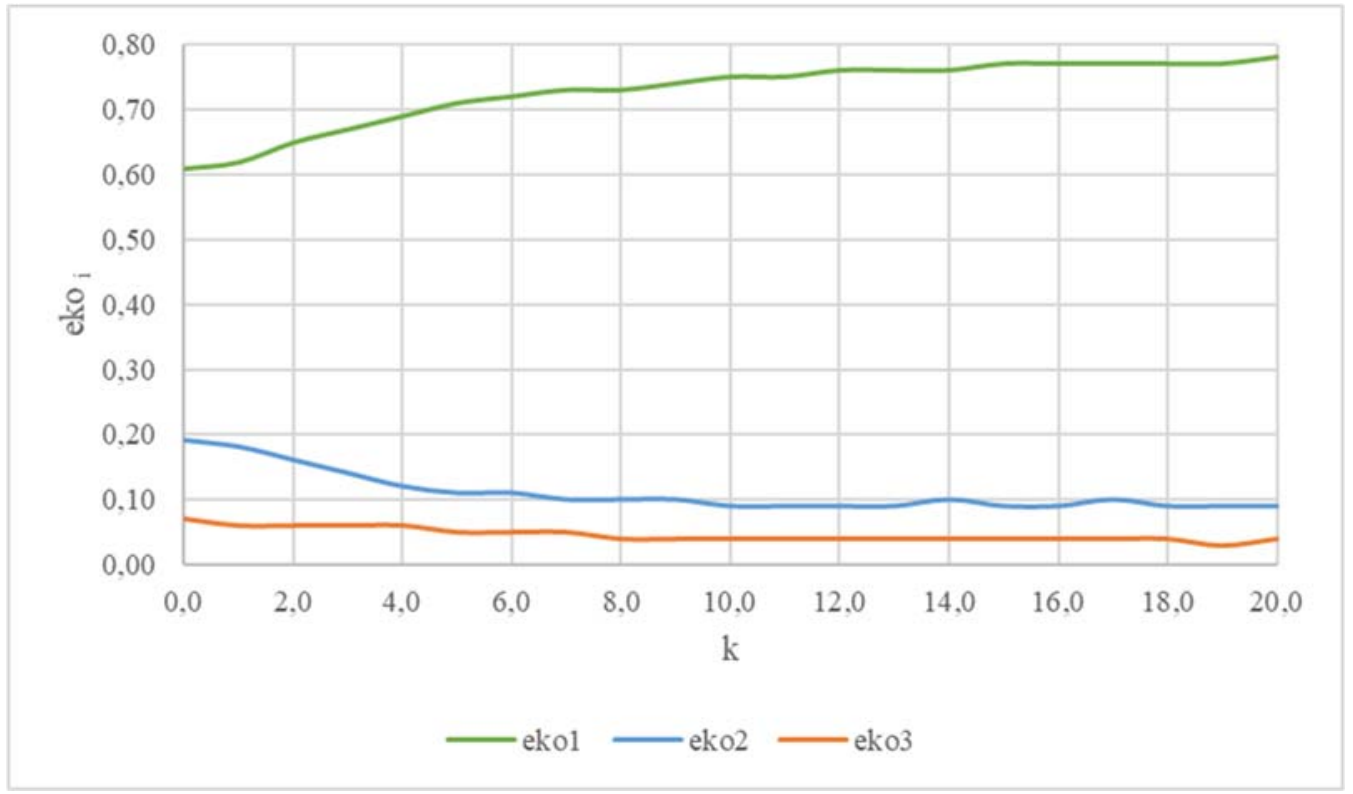

Şekil 4. İlk üç mod için etkin kütle oranı (eko) değerleri

Tasarıma esas tepe noktası yer değiştirmeleri ise ilk üç moddaki büyüklükler dikkate alınarak karelerinin toplamının karekökü yöntemiyle aşağıdaki gibi bulunur.

$d=\sqrt{\operatorname{dep}_{1}{ }^{2}+\operatorname{dep}_{2}{ }^{2}+\operatorname{dep}_{3}{ }^{2}}$

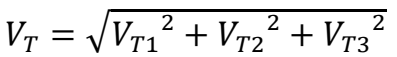

Sunulan yöntemin akışşeması Şekil 5’te verilmiştir.

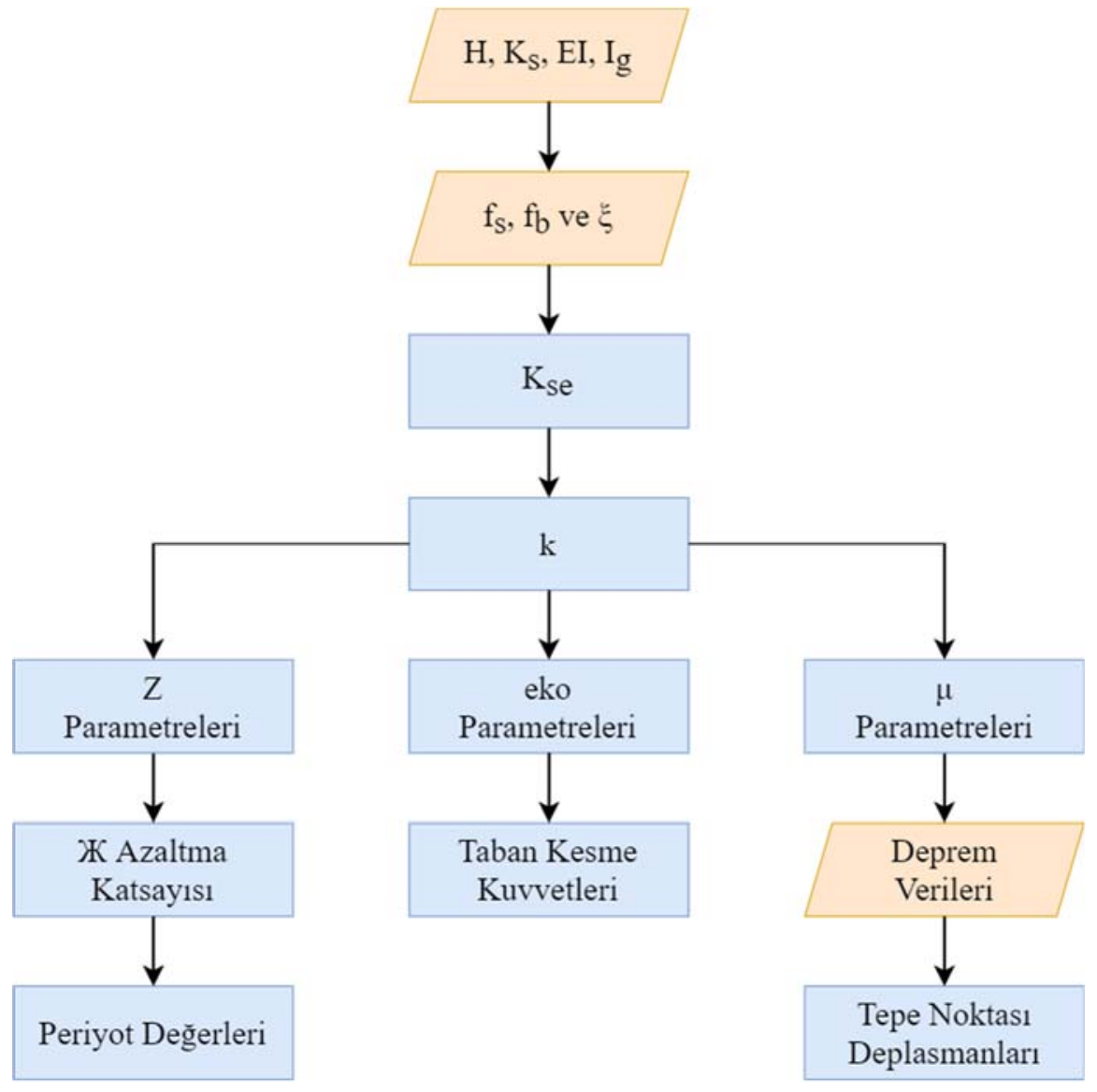

Şekil 5. Akış şeması 


\section{3. ÖRNEK}

Literatürden [17] alınan modelin planı ve kesiti Şekil 6 ve Şekil 7'de görülmektedir. Çelik binanın özellikleri Tablo 1'de verilmektedir. Tablo 2'de ise kolon ve kirişlerde kullanılan profillerin özellikleri verilmiștir.

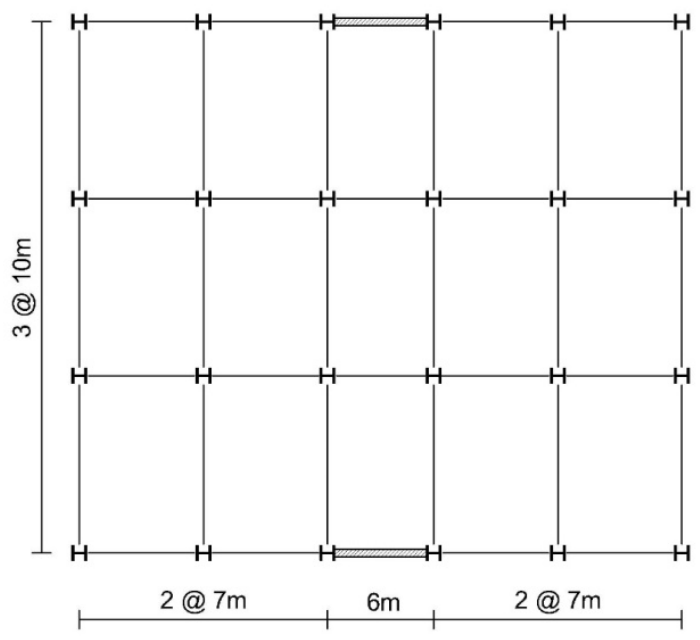

Şekil 6. Bina plan görünüşü

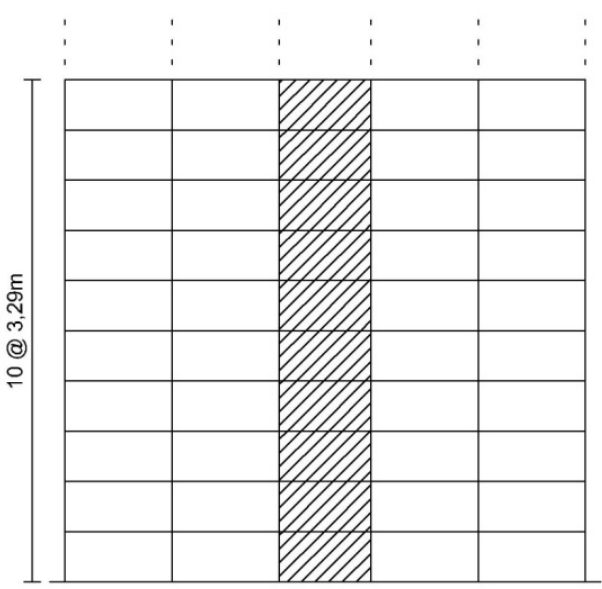

Şekil 7. On kata kadar bina ön cephe görünüşü

Tablo 1. Bina özellikleri

\begin{tabular}{cc}
\hline Kat Sayısı & 40 \\
\hline Kat Yüksekliği $(\mathbf{m})$ & 3,29 \\
\hline ÇLPD Kalınlı̆̆ı $(\mathbf{m m})$ & 6 \\
\hline ÇLPD Genişliği $(\mathbf{m})$ & 6 \\
\hline Kolonlar & HD $400 \times 347$ \\
\hline Kirişler & HE400A \\
\hline
\end{tabular}


Tablo 2. Profil Özellikleri

\begin{tabular}{|c|c|c|}
\hline Profil & HD400 $\times 347$ & HE400A \\
\hline Yükseklik (mm) & 407 & 390 \\
\hline Üst Flanş Genişliği (mm) & 404 & 300 \\
\hline Üst Flanş Kalınlığı (mm) & 43,7 & 19 \\
\hline Gövde Kalınlığı (mm) & 27,2 & 11 \\
\hline Alt Flanş Genişliği (mm) & 404 & 300 \\
\hline Alt Flanş Kalınlığı (mm) & 43,7 & 19 \\
\hline Alan $\left(\mathrm{cm}^{2}\right)$ & 442 & 159 \\
\hline Atalet momenti $\left(\mathrm{cm}^{4}\right)$ & 124900 & 45070 \\
\hline
\end{tabular}

Verilen binanın Türkiye Bina Deprem Yönetmeliği [18] kapsamında mod birleştirme yöntemine göre analizi hem sürekli sistem hesap modeli hem de SAP2000 ile yapılarak sonuçlar karşılaştırılmıştır. Binanın Çanakkale il merkezinde ZE zemin sınıfı üzerinde inşa edildiği kabul edilmiştir. Türkiye deprem tehlike haritaları interaktif web uygulamasından Çanakkale ili için yatay spektrum değerleri elde edilmiş olup, buna ilişkin deprem verileri Tablo 3'te verilmiştir.

Tablo 3. Deprem verileri

\begin{tabular}{cc}
\hline $\begin{array}{c}\text { Deprem Yer } \\
\text { Hareketi Düzeyi }\end{array}$ & DD-2 \\
\hline Yerel Zemin Sinıfi & ZE \\
\hline Enlem & $40.143295^{\circ}$ \\
\hline Boylam & $26.446727^{\circ}$ \\
\hline $\mathbf{S}_{\mathbf{S}}$ & 0,719 \\
\hline $\mathbf{S}_{\mathbf{1}}$ & 0,219 \\
\hline $\mathbf{F}_{\mathbf{S}}$ & 1,350 \\
\hline $\mathbf{F}_{\mathbf{1}}$ & 3,205 \\
\hline $\mathbf{S}_{\mathbf{D S}}$ & 0,970 \\
\hline $\mathbf{S}_{\mathbf{D} 1}$ & 0,702 \\
\hline $\mathbf{T}_{\mathbf{A}}(\mathbf{s})$ & 0,145 \\
\hline $\mathbf{T}_{\mathbf{B}}(\mathbf{s})$ & 0,723 \\
\hline $\mathbf{T}_{\mathbf{L}}(\mathbf{s})$ & 6,000 \\
\hline
\end{tabular}

Binanın süneklik düzeyi yüksek çelik taşıyıcı sistemlerden oluştuğu kabul edilmiş olup taşıyıcı sistem davranış katsayısı $\mathrm{R}=6$ ve dayanım fazlalığı katsayısı $\mathrm{D}=2.5$ olarak alınmıştır. Aşağıda Şekil 8'de hesaplarda dikkate alınan azaltılmış yatay spektrum grafiği verilmiştir. 


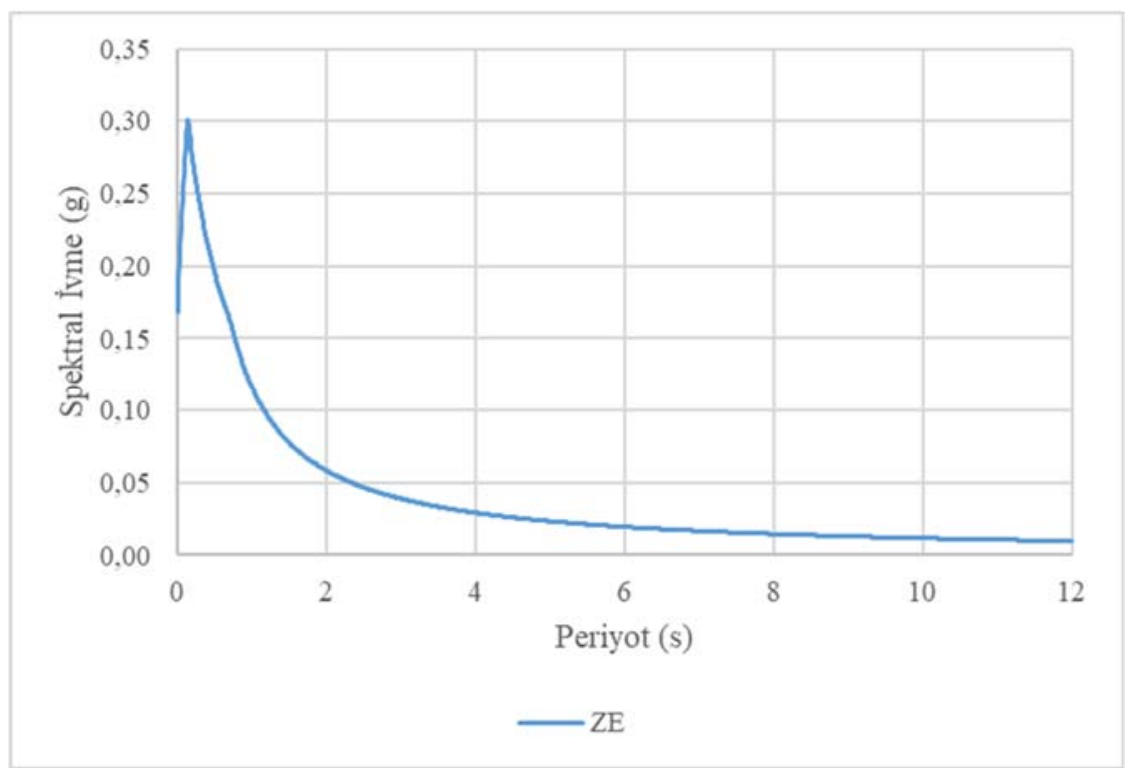

Şekil 8. Azaltılmış yatay spektrum grafiği

Verilen binanın serbest titreşim analizi ve TBDY'ye göre spektral analizi SAP2000 programı kullanılarak yapılmıştır. Modellemede perdeler kabuk elemanlarla buna karşı kiriş ve kolonlar ise çubuk elamanlara modellenmiştir. Şekil 9'da SAP2000'de oluşturulan modelin xz ve yz eksenlerindeki görünüşleri ile üç boyutlu görünüşü verilmiştir.
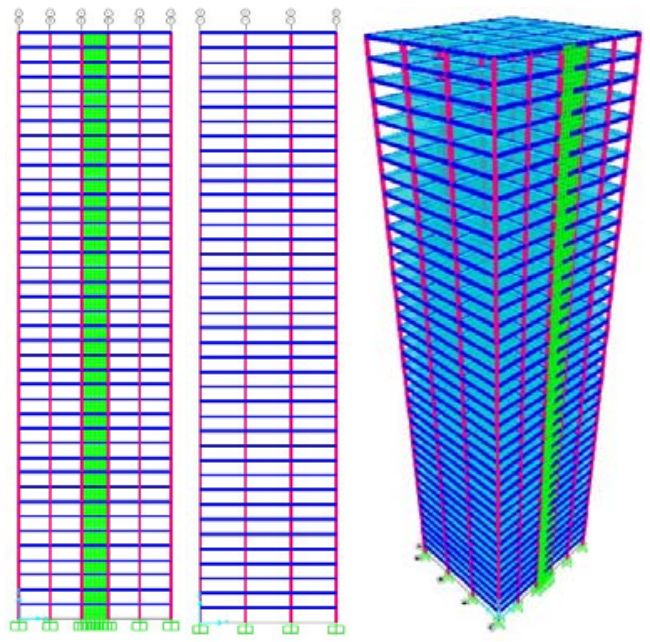

Şekil 9. Binanın xz ve yz eksenlerindeki görünüşleri ile üç boyutlu modeli (Sap2000)

\subsection{Sürekli Sistem Hesap Modeline Göre Periyot, Taban Kesme Kuvveti ve Tepe Noktası Deplasman Hesabı}

Sürekli sistem hesap modeline göre çözümleme için gerekli olan parametreler literatürden [17] yararlanılarak bulunmuştur. Bina yüksekliği boyunca yayılı kütle 76 ton/m'dir. Bilindiği üzere TBDY-2018'e göre analizlerde kolon kiriş ve perdelerde etkin kesit rijitliklerinin kullanılması gerekmektedir. Buna göre hesaplanmış rijitlikler ve bina yüksekliği boyunca yayıllı kütle değerleri Tablo 4 'te verilmiştir.

Tablo 4. Etkin kesit rjitlikleri dikkate alınarak hesaplanan eşdeğer rijitlikler

\begin{tabular}{cc}
\hline $\mathbf{K}_{\mathbf{s}}(\mathbf{k N})$ & 97200 \\
\hline $\boldsymbol{\xi}$ & 0,9544 \\
\hline $\mathbf{K}_{\mathbf{s e}}(\mathbf{k N})$ & 92820 \\
\hline $\mathbf{E I}\left(\mathbf{k N m}^{\mathbf{2}}\right)$ & 99599440 \\
\hline $\mathbf{H}(\mathbf{m})$ & 131,6 \\
\hline $\mathbf{k}$ & 4,018
\end{tabular}


Bulunan k değerine bağlı olarak Şekil 2, Şekil 3 ve Şekil 4'ten okunan Z, $\mu$ ve eko değerleri ile Şekil 8'de verilmiş spektrumdan okunan spektral ivme ve spektral yer değiştirme değerleri Tablo 5 'te ilk üç mod için verilmiştir.

Tablo 5. TBDY-2018 hesap modeli için seçilen değerler

\begin{tabular}{cccc}
\hline & \multicolumn{3}{c}{ MOD NUMARASI } \\
\hline $\mathbf{Z}_{\mathbf{i}}$ & $\mathbf{1}$ & $\mathbf{2}$ & $\mathbf{3}$ \\
\hline $\boldsymbol{\mu}_{\mathbf{i}}$ & 0,742035 & 0,199617 & 0,088896 \\
\hline $\mathbf{e k o}_{\mathbf{i}}$ & 1,429304 & $-0,69930$ & 0,470000 \\
\hline $\mathbf{S}_{\mathbf{a} \mathbf{i}}$ & 0,690348 & 0,119826 & 0,059826 \\
\hline $\mathbf{S}_{\mathbf{d} \mathbf{i}}$ & 0,099 & 0,369 & 0,832 \\
\hline & 0,335 & 0,09 & 0,04
\end{tabular}

Z değerleri yardımıyla (9) nolu bağıntı kullanılarak periyotlar bulunmuş ve Tablo 6 ve Şekil 10'da SAP2000 ile elde edilen periyotlarla karşılaştırılmıştır.

Tablo 6. Etkin kesit rijitlikleri dikkate alınarak bulunan periyotlarının karşılaştırılması

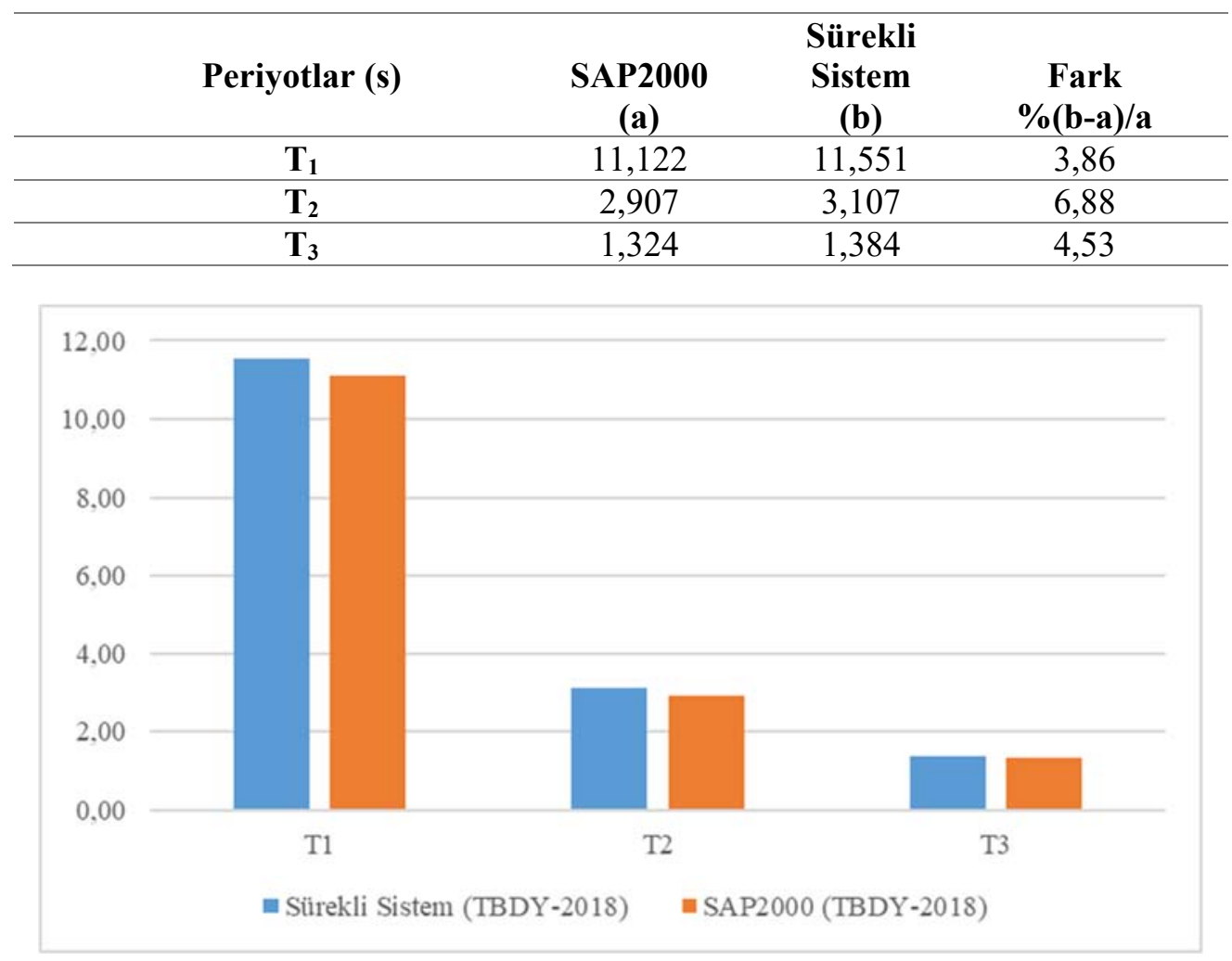

Şekil 10. Etkin kesit rijitlikleri dikkate alınarak bulunan periyotlarının karşılaştırılması

(16), (17), (18) ve (19) nolu bağıntılar kullanılarak taban kesme kuvveti ve tepe noktası deplasmanı hesaplanarak elde edilen sonuçlar SAP2000 ile elde edilen sonuçlarla Tablo 7'de karşılaştırılmıştır.

Tablo 7. TBDY-2018'e göre taban kesme kuvvetleri ve tepe noktası deplasmanların karşılaştırılması

\begin{tabular}{cccc}
\hline Çözümleme & $\begin{array}{c}\text { SAP2000 } \\
\text { (a) }\end{array}$ & $\begin{array}{c}\text { Sürekli } \\
\text { Sistem } \\
(\mathbf{b})\end{array}$ & $\begin{array}{c}\text { Fark } \\
\text { \% (b-a)/a }\end{array}$ \\
\hline $\mathbf{V}_{\mathbf{T}}(\mathbf{k N})$ & 2158,099 & 1908,254 & -11.58 \\
\hline $\mathbf{d}_{\mathbf{H}}(\mathbf{m})$ & 0,4728 & 0,4833 & 2.22 \\
\hline
\end{tabular}

Tablo 7'den görüldüğü üzere sürekli sistem hesap modeli ile bulunan tepe noktası deplasmanı değeri SAP2000 ile bulunan değerle uyumludur buna karşın sürekli sistem hesap modeli ile bulunan taban kesme kuvveti değeri SAP2000 ile bulunan değerden daha azdır. Bunun sebebi sürekli sistem hesap modelinde yalnızca 3 mod dikkate 
alınması olarak değerlendirilmiştir. Taban kesme kuvvetinin elde edilmesinde 4. ve 5. modların katkısı ihmal edilemeyecek mertebededir. Buna karşı tepe noktası deplasmanında 3.ten yüksek modların katkısı ihmal edilebilecek mertebededir. Aynı örneğin literatürde yapılan çözümünde hakim periyot brüt kesit rijitlikleri ile hesaplanmıştır. Bu nedenle örneğin brüt rijitlikleri dikkate alınarak periyotları tekrar hesaplanarak sonuçlar karşılaştırılmıştır. Tablo 8'de brüt kesit rijitlikleri ile hesaplanan eşdeğer rijitlikler verilmiştir.

Tablo 8. Brüt kesit rijitlikleri dikkate alınarak hesaplanan eşdeğer rijitlikler

\begin{tabular}{cc}
\hline $\mathbf{K}_{\mathbf{s}}(\mathbf{k N})$ & 97200 \\
\hline $\boldsymbol{\xi}$ & 0,88 \\
\hline $\mathbf{K}_{\mathbf{s e}} \mathbf{( k N )}$ & 238000 \\
\hline $\mathbf{E I}\left(\mathbf{k N m} \mathbf{2 N}^{\mathbf{2}}\right.$ & 197800000 \\
\hline $\mathbf{H} \mathbf{( m )}$ & 131,6 \\
\hline $\mathbf{k}$ & 4,56
\end{tabular}

Bulunan k değerine bağlı olarak Şekil 2'den Z değerleri okunmuştur. İlk üç mod için okunan Z değerleri Tablo 9'da verilmiştir.

Tablo 9. Sürekli sistem hesap modeli için seçilen $\mathrm{Z}$ değerleri

\begin{tabular}{cccc}
\hline & $\mathbf{1}$ & $\mathbf{2}$ & $\mathbf{3}$ \\
\hline $\mathbf{Z}_{\mathbf{i}}$ & 0,680494 & 0,187636 & 0,085628 \\
\hline
\end{tabular}

Z değerleri yardımıyla (9) nolu bağıntı kullanılarak periyotlar bulunmuş ve Tablo 10 ve Şekil 11'de SAP2000 Literatür ile elde edilen periyotlarla karşılaştırılmıştır.

Tablo 10. Brüt kesit dikkate alınarak bulunan periyotların karşılaştııılması

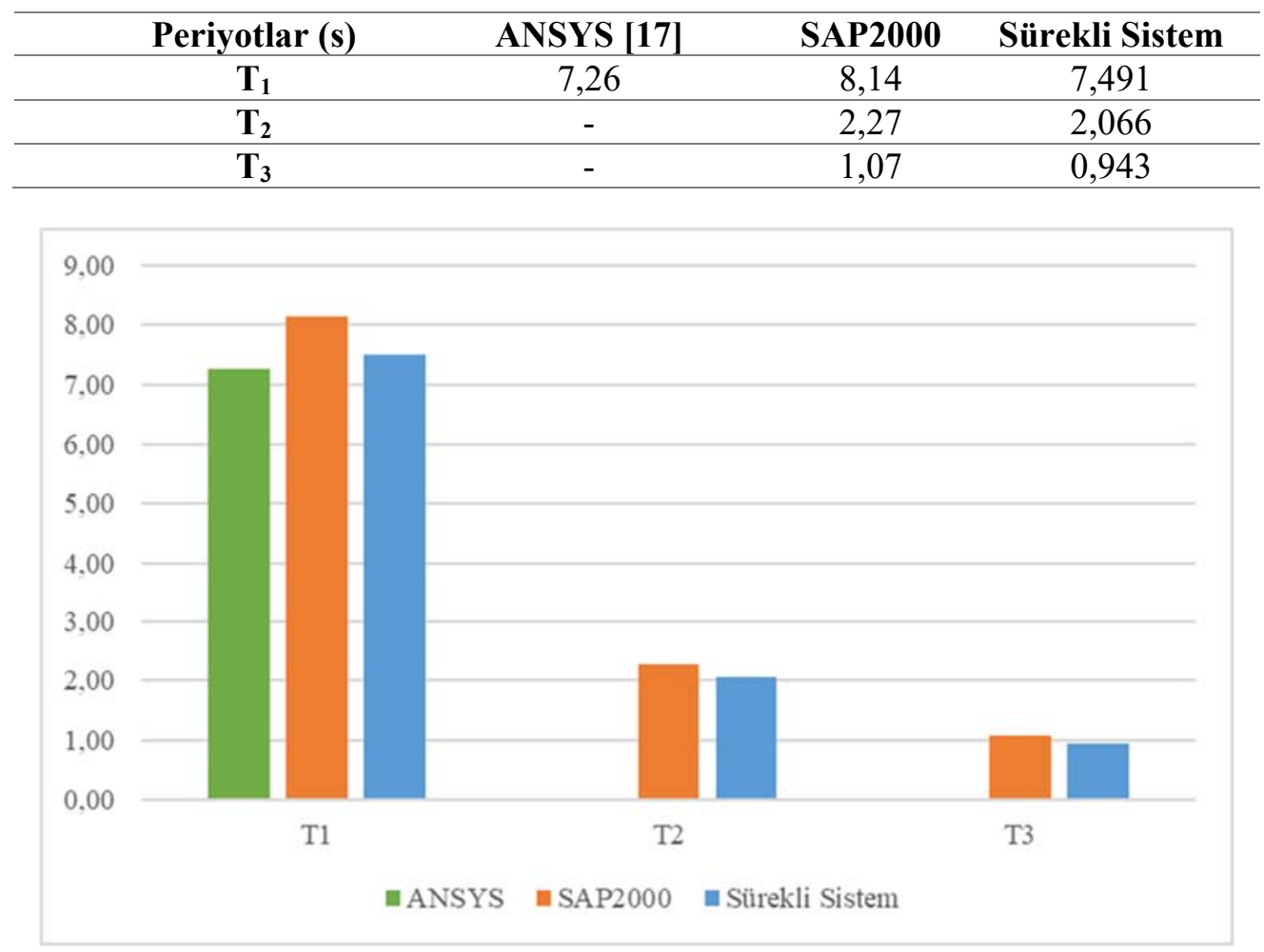

Şekil 11. Brüt kesit dikkate alınarak bulunan periyotların karşılaştırılması

\section{SONUÇ}

Bu çalışmada çelik levhalı perde-çerçeve sistemlerin dinamik analizi için sürekli sistem hesap modeli önerilmiştir. Önerilen yöntem ile periyotlar, etkin kütle oranları gibi dinamik karakteristikler pratik bir şekilde elde edilmektedir. Ayrıca bu dinamik parametreler kullanılarak spektral analiz yöntemiyle taban kesme kuvveti ve tepe noktası deplasmanı da kolayca hesaplanmaktadır. Çalışmanın sonunda literatürden alınan bir örnek hem 
SAP2000 hem de sunulan yöntem ile çözülmüştür. Sürekli sistem ile elde edilen sonuçlar literatür ve SAP2000 ile elde edilen sonuçlarla karşılaştırılmıştır.

Elde edilen sonuçlardan, sunulan yöntemin yeter derecede uygun sonuçlar verdiği görülmüştür. Sonuç olarak sunulan yaklaşım ön boyutlandırma aşamasında ve yapısal analiz yapan programların çıktılarının kontrolünde kullanılabilir. Ayrıca çalışma kapsamında sunulan yöntem ile az bir parametre ile bina davranışı hakkında fikir edinmek mümkün olmakta ve sonlu elemanlar yönteminde çıktıların fazlalığı nedeniyle gözden kaçan bina davranışı daha iyi anlaşılmaktadır. Sunulan yöntem burulmalı ve bina özellikleri yüksekliği boyunca değişen binalar içinde geliştirilebilir.

\section{Yazar Katkıları}

İki yazarın katkısı da eşit olup \%50'dir.

\section{Çıkar Çatışması}

Makale yazarları aralarında herhangi bir çıkar çatışması olmadığııı beyan ederler

\section{KAYNAKÇA}

[1] R. J. Love, K. Yu, S. McNeill and D. Zepeda, "Retrofit of a critical care facility in los angeles with steel plate shear walls", in Structures Congress 2008: Crossing Borders, Vancouver, Canada, 2008.

[2] A. K. Bhowmick, R. G. Driver and G. Y. Grondin, "Application of indirect capacity design principles for seismic design of steel-plate shear walls", Journal of Structural Engineering, vol. 137, no. 4, pp. 521-530, 2011.

[3] E. Alavi and F. Nateghi, "Experimental study of diagonally stiffened steel plate shear walls", Journal of Structural Engineering, vol. 139, no. 11, pp. 1795-1811, 2013.

[4] J. G. Nie, L. Zhu, J. S. Fan and Y. L. Mo, "Lateral resistance capacity of stiffened steel plate shear walls", Thin-Walled Structures, vol. 67, pp. 155167,2013

[5] M. Koppal and M. R. Eatherton, "Perforated Steel Plate Shear Walls for Tunable Seismic Resistance", in Structures Congress 2013: Bridging Your Passion with Your Profession, Pittsburgh, Pennsylvania, 2013.

[6] A. K. Bhowmick, G. Y. Grondin and R. G. Driver, "Nonlinear seismic analysis of perforated steel plate shear walls", Journal of Constructional Steel Research, vol. 94, pp. 103-113, 2014.

[7] M. H. Asl and M. Safarkhani, "Seismic behavior of steel plate shear wall with reduced boundary beam section", Thin-Walled Structures, vol. 116, pp. 169179, 2017.

[8] D. M. Dowden and M. Bruneau, "Dynamic shaketable testing and analytical investigation of selfcentering steel plate shear walls", Journal of Structural Engineering, vol. 142, no. 10, 2016.

[9] X. T. Wang and C. D. Xie, "Experimental and numerical investigation of steel beam-to-cfst column frame-thin steel plate shear walls with cross stiffness", International Journal of Steel Structures, vol. 19, pp. 1895-1910, 2019.
[10] J. G. Yu, X. T. Feng, B. Li and J. P. Hao, "Cyclic performance of cross restrained steel plate shear walls with transverse braces", Thin-Walled Structures, vol. 132, pp. 250-264, 2018.

[11] V. N. Baikov and E. E. Sigalov, "Reinforced Concrete Structures", MIR Publishers, 1981.

[12] K. B. Bozdoğan, D. Öztürk and A. Nuhoğlu, “A practical method for dynamic analysis of multistorey buildings according to continuum approximation model", Journal of Engineering and Natural Sciences, 2005.

[13] B. S. Smith and E. Crowe, "Estimating periods of vibration of tall buildings", Journal of Structural Engineering, vol. 112, no. 5, pp. 1005-1019, 1986.

[14] S. Bilyap, "Betonarme Yüksek Yapılarda Perde Çerçeve Sistemlerinin Yatay Kuvvetlere Göre Hesabı”, Ege Üniversitesi Matbaas1, 1979.

[15] Y. Ertutar and B. Arısoy, "Computation of the shear stiffness for the combined shear wall with multi span systems", Housing Science, vol. 18, pp. 105-112, 1994.

[16] K. A. Zalka, "A simplified method for calculation of the natural frequencies of wall-frame buildings", Engineering Structures, vol. 23, pp. 1544-1555, 2001.

[17] C. Topkaya and C. O. Kurban, "Natural periods of steel plate shear wall systems", Journal of Constructional Steel Research, vol. 65, pp. 542-551, 2009.

[18] Afet ve Acil Durum Yönetimi Başkanlığı, Türkiye Bina Deprem Yönetmeliği, Ankara, 2018. 